\title{
Characterization of gliding text as a reading stimulus
}

\author{
MARTIN BUETTNER, C. C. KRISCHER, and R. MEISSEN \\ Institute of Neurobiology, Nuclear Research Center, Jülich, West Germany
}

(Charles W. Eriksen, sponsor)

\begin{abstract}
Eye movement is analyzed for reading one line of text gliding smoothly across a television screen. The resulting eye movement pattern is similar to optokinetic nystagmus. Unlike for normal reading, the eye fixations recorded for reading gliding text are nonstationary pursuit fixations on a moving target. The slower reading speed measured for gliding than for stationary text may indicate that an extra effort is needed to maintain optokinetic nystagmus in the process of reading.
\end{abstract}

Normal eye movement patterns in the reading of printed material consist of regular 1.3-word forward steps (saccades) every $250 \mathrm{msec}$ followed by long return sweeps and repositioning saccades at the end of lines. Reading speeds commonly reach a range of 250-300 words per minute (WPM). The rate-determining components of the reading process are assumed to be linguistic processing and comprehension (Tinker, 1966).

Rapid serial visual presentation (RSVP) is a different type of reading stimulus. In RSVP, the retina is stimulated by sequentially flashing the words of a sentence rapidly at a constant location (Forster, 1970; Gilbert, 1959; Potter, Kroll, \& Harris, 1980). RSVP requires no eye movement. The speeds that can be achieved with correct oral reading and normal comprehension do not exceed normal reading speeds (Ward \& Joula, 1982). Fasterthan-normal reading speeds are probably hindered by phenomena like masking (Bridgeman, 1971; Eriksen \& Schultz, 1978) and the lack of visual feedback (Hannaford, Krischer, \& Stark, 1984).

Smoothly gliding text, such as that used on the Times Square news marquee advertisement in New York City, is another reading stimulus. Since few words are presented at one time, only relatively small displays are needed (Newman, 1966; Weigelin, Trier, Krischer, \& Meissen, 1979). The compactness of the display and the attentionattracting movement make this stimulus well suited for advertising. Because of these properties, moving gratings have even been tried for the objective determination of visual acuity (Pearson, 1966), and gliding text has been used as an effective reading aid to patients with poor vision (Weigelin et al., 1979).

This investigation was supported initially by Deutsche Forschungsgemeinschaft Grant $\mathrm{Kr} / 284-8$. The authors are indebted to L. Stark \& A. Jones, School of Optometry, University of California at Berkeley, for helping with the experiments, to Leonard J. Peltier for his careful revision of the manuscript, and to D. I. K.-F. Rittinghaus and H. Stieve for their support of this work. The authors' mailing address is: Institute of Neurobiology, Nuclear Research Center, D 5170 Jülich, West Germany.
Although gliding text has been used in advertising for a long time, very little is known about the reading mechanism behind it. The slow glide speeds used, 100 WPM (Newman, 1966), in contrast with the rapid speeds used in RSVP, up to 1,200 WPM (Forster, 1970), indicate that the mechanism for reading gliding text is probably not a zero eye movement mechanism, as has been suggested (Rayner, 1978).

The aim of this investigation was to measure eye movement parameters for reading gliding text and to make a preliminary classification of this type of reading with respect to other reading modes such as reading RSVPgenerated or stationary text. To facilitate the comparison of gliding text data with conventional reading data, the fundamental eye movement parameters of saccade length and fixation duration were measured. Finally, an attempt was made to suggest potential scientific and practical applications for gliding text.

\section{METHODS}

\section{Apparatus}

Text display. An electronic TV text display device developed at the Nuclear Research Center (Kernforschungsanlage, KFA) in Jülich (Weigelin et al., 1979) was used to display both the gliding and stationary texts. The instrument, essentially a modified personal computer, was capable of storing up to 4,000 characters in its electronic memory and could display this text on a 66-cm (26-in.) diagonally measured TV screen. "Light" characters (luminance approximately $100 \mathrm{~cd} / \mathrm{m}^{2}$ ) were displayed against the "dark" screen (luminance approximately $5 \mathrm{~cd} / \mathrm{m}^{2}$ ). The height of the characters subtended an angle of $0.42^{\circ}$. Forty-eight characters could be displayed at one time.

Text advancement. A remote control unit connected to the TV text display device enabled the subjects to choose among four glide speeds: $37,74,148$, or 296 WPM. It also allowed stationary text to be instantaneously advanced one line (48 characters, with a 6-character overlap). By releasing the speed button on the remote control unit, the gliding text could be momentarily stopped.

Eye movement recording. A commercial infrared cornea-sclera reflection device (Stark, Vossius, \& Young, 1962), manufactured in Applied Science Laboratories, Waltham, MA), was used to measure horizontal eye movement. A two-channel strip chart recorder served to record the data. One channel registered the advancement of characters in the instrument's memory, and the other channel registered the corresponding eye movements. 


\section{Procedures}

Subjects. Six subjects with normal visual acuity $(20 / 20=100 \%)$ and with normal or corrected refraction were chosen from the graduate students and staff of the KFA in Jülich. The subject group consisted of both males and females and ranged in age from 23 to 47 years.

Text. Elementary short stories from the German version of Reader's Digest were typed into the 4,000-character buffer store of the electronic TV text display device. A remote control unit could retrieve these data and adapt them for either stationary or gliding text display. The subjects were asked to find a comfortable oral reading speed that would allow them to read each word correctly.

The two important eye movement parameters for reading stationary text, saccade length and fixation duration, were calculated for each subject by averaging, respectively, (1) the amplitudes and (2) the durations of the regular, staircase-like reading patterns over 3-5 lines of text (see Figure 1).

For gliding text, the duration of one gliding fixation plus the corresponding duration of a saccade was obtained by measuring the total time for 30-50 pursuit movements and dividing this time by the respective number of events. The second parameter, the saccade length, the span, was calculated by dividing the total number of recorded characters by the corresponding number of events. Since only a few recordings were thus needed, the subjects usually read only $150-400$ words for each paradigm.

\section{RESULTS}

Recordings of the eye movements during oral reading of one line of stationary text yielded regular, staircaselike forward saccades in the middle of each line and irregular, longer-than-average fixations at the beginning and end of the line (see Figure 1, Record 2). By skipping these irregular first and last fixations and the backward saccades, that is, the regressions (indicated by arrows in Figure 1), data that were representative for the ideal case of reading an infinite line of text were obtained. The parameters measured by this procedure are as follows (mean values for six subjects \pm standard deviation): (1) $289 \pm 32 \mathrm{msec}$ for the duration of a fixation plus the corresponding duration of a saccade; (2) a saccade length of $6.2 \pm 0.9$ characters, including blanks (a little more than one word); and (3) $214 \pm 51$ WPM.

A typical recording of eye movements for reading gliding text shows two features very similar to optokinetic nystagmus (see Figure 1, Record 3): (1) The eye briefly fixates and follows the moving target and then (2) jumps back to the next piece of text. Regressions are also observed occasionally (see arrow in Figure 1, Record 3).

Large excursions of the eye position from the center of the screen occurred when the speed control appeared to be too fast. The subjects could then sustain correct reading only if they slowed or even interrupted the gliding advancement of text. These irregularities for the reading of gliding text were excluded from the evaluations. When a steady-state reading of the gliding text was achieved, as evidenced by the gaze remaining near the center of the screen, the reading speed was obtained by dividing the number of characters advanced per saccade by the duration of one pursuit unit. The mean saccadic length was obtained by dividing the steady-state reading speed by the measured fixation duration. The results are as follows:
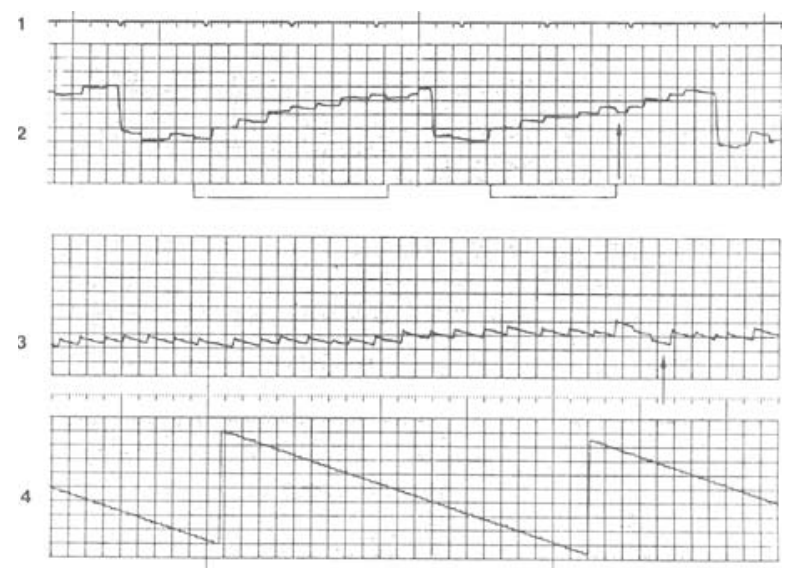

Figure 1. Pattern of saccadic eye movement for oral reading; amplitude is plotted against time. Record 1: Time scale is in seconds. Record 2: Typical staircase-pattern record for reading conventional page-structured text with approximately 50 characters per line. The eyes move stepwise from left (bottom) to right (top) and then return to the beginning of the next line with a long leftward saccade. Note the irregular orientation saccades after the return sweeps, and note the intermittent regressions (the arrow indicates a regression). To obtain eye movement parameters comparable to those for the gliding endless line (Record 3), only the regular central parts of the staircases above the square brackets were evaluated. Record 3: Eye movement pattern for reading one line of gliding text. The pattern resembles optokinetic nystagmus: Leftward slow pursuit movements alternate with rightward saccades. The subject fixates on the text during the pursuit movements. The arrow indicates a regression (not evaluated). Record 4: Readout of the instrument's electronic memory store registering the glide speed. The subject controls the glide speed by means of a remote control unit. The record contains two automatic resets after the passage of 64 characters. During the recording period shown, the glide speed of text remained constant at 148 WPM.

(1) $314 \pm 27 \mathrm{msec}$ for the duration of one gliding fixation plus the duration of the corresponding saccade; and (2) a reading speed of $164 \pm 25 \mathrm{WPM}$. The calculations described above yield a mean saccadic length of: (3) 5.2 characters, including blanks (about one word). Figure 2 is a graphic comparison of the reading speeds measured for stationary and for gliding text.

Reading speed for the ideal case of reading an endless line of stationary text (left side, hatched bars) was found to be about $25 \%$ faster than reading gliding text (left side, plain bars). This relationship, however, is valid only when important parameters such as regressions and return sweeps are excluded.

In the nonideal reading case, both the reading speeds for gliding text and stationary text have to be reduced (see right side of Figure 2). Regressions-see arrow in Figure 1 -typically account for a $10 \%$ loss of reading speed (Tinker, 1966). Return sweeps and repositioning saccades typically account for another $10 \%$ reduction in the reading speed for stationary text (Tinker, 1966). The advantage of reading an endless line of stationary text, as com- 


\section{RETURN SWEEPS AND REGRESSIONS}

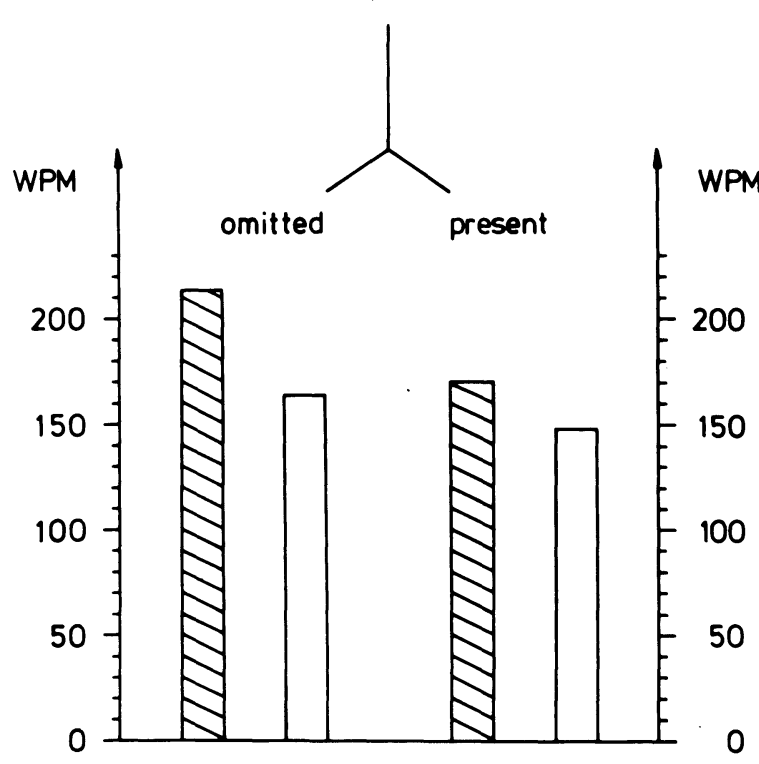

Figure 2. Comparison of reading speeds averaged for six subjects for reading aloud stationary and gliding text (hatched and plain bars, respectively). Left side: Hypothetical reading of an endless line; that is, return sweeps to the new line, orientation saccades, and regressions were omitted. Right side: Real reading situation. A $10 \%$ reduction of reading speed is allowed for regressions. For reading stationary text, an additional reduction of the speed by $10 \%$ accounts for the return sweeps and orientation saccades for each new line. See Record 2 in Figure 1. Note: Under idealized endless-line reading conditions (left side of chart), stationary text is read about 25\% faster than gliding text. For conventional reading, subjects lose time in the long return sweeps, regressions, and orientation saccades; therefore, the difference in speed between gliding and stationary text is diminished (right side of chart).

pared with reading an endless line of gliding text, is, therefore, noticeably diminished (see right side of Figure 2).

\section{DISCUSSION}

The eye movement patterns for the reading of gliding text measured in this experiment are similar to the pattern measured for optokinetic nystagmus (Carpenter, 1977). Steadily moving targets such as gratings or gliding text are so attention attracting that their use for the objective determination of visual acuity (Pearson, 1966) and for advertising becomes understandable.

The data indicates that both the reading of normal stationary text and the reading of gliding text are based on regular saccadic eye movements. The 5.2-character saccade length for reading gliding text is about $16 \%$ smaller than the saccade length for reading conventional stationary text. In reading gliding text, subjects fixate $9 \%$ longer than they do in reading the idealized stationary text. Both the difference in saccade length and fixation duration contribute to the $25 \%$ slower reading speed for gliding than for stationary text.

Since all subjects have had life-long experience in conventional reading but only a very brief encounter with gliding text, and since the effect of practice has not yet been investigated, only limited conclusions may be drawn from the observed differences in reading an idealized endless line of stationary text and a gliding endless line of text.
It can be speculated, however, that there are endogenic reasons for the lesser reading speed of gliding than for stationary text. Possible reasons for the reduction of speed are that extra effort is required to coordinate the reversal of eye direction from leftward pursuit to rightward saccadic step (McConkie, 1983) and that tracking a moving target is more difficult. Assuming that stationary reading requires a subject's complete attention, the drop of reading speed for reading gliding text can also be understood, since the reader's attention must be shared by the reading process and the maintenance of optokinetic nystagmus.

The eye movement patterns for reading gliding text must be classified between the patterns for reading normal and reading RSVP-generated texts. The degrees of freedom for eye movements vary characteristically for the three types of reading. RSVP reading is quasi-zero dimensional: The eyes do not move, no regressions are possible, and visual feedback is excluded. Reading gliding text is quasi-one-dimensional: Vertical orientation problems are minimal and visual feedback is possible to a limited extent. Reading conventional text is fully twodimensional: Both horizontal and vertical eye movements are possible, and the subject has full visual feedback. For normally sighted subjects, typographic measures have helped to minimize orientation problems on a page (Tinker, 1966).

Because of the unique properties that can be achieved with the gliding text stimulus-the absence of a multiple line structure, the enforced steady-state reading speed, the arbitrary letter size, and the restrictable window size-it may prove valuable in the scientific study of new aspects in the reading process. It may also offer useful practical applications aside from advertising.

(1) For the visually handicapped, who generally need large-print text to compensate for their loss of visual resolution (Sloan \& Habel, 1973), the arbitrary letter size and continuous presentation capabilities of a gliding text device would allow patients with poor visual acuity [i.e., 20/200 $(10 \%)]$ to avoid the long sweeps (of up to $150^{\circ}$ ) that disrupt their ability to read smoothly. The single-line structure would be especially useful to patients who tend to mistrack and thus lose whole lines of text.

(2) A gliding text display may also prove useful for long-term therapy and reading training of persons with severe reading difficulties. One remedial application relies on the variable window size. This had been suggested more than 40 years ago (Taylor, 1937). By limiting the window to a few letters, it might be possible to suppress the erratic eye movements observed in some patients with specific dyslexia (Jones \& Stark, 1983).

\section{REFERENCES}

Bridgeman, B. (1971). Metacontrast and lateral inhibition. Psychological Review, 78, 528-539.

Carpenter, R. H. S. (1977). Movements of the eye. London: Pion.

ERIKSEN, C. W., \& SchUlTZ, D. (1978). Temporal factors in visual information processing: A tutorial review. In J. Requin (Ed.), Attention and performance VII. Hillsdale, NJ: Erlbaum.

FORSTER, K. I. (1970). Visual perception of rapidly presented word sequences of varying complexity. Perception \& Psychophysics, 8, 215-221.

GILBERT, L. C. (1959). Saccadic movements as a factor in visual perception in reading. Journal of Educational Psychology, 50, 15-19.

Hannaford, B., Krischer, C. C., \& Stark, L. A. (1985). A device for zero eye movement reading. IEEE Transactions of Biomedical Engineering, BME-32, 86-89.

JoNES, A., \& STARK, L. (1983). Abnormal patterns of normal eye movements in specific dyslexia. In K. Rayner (Ed.), Eye movements in reading: Perceptual and language processes. New York: Academic Press.

McCoNKIE, G. W. (1983). Eye movements and perception during reading. In K. Rayner (Ed.), Eye movements in reading: Perceptual and language processes. New York: Academic Press.

Newman, E. B. (1966). Speed of reading when the span of letters is restricted. American Journal of Psychology, 79, 272-278.

Pearson, R. M. (1966). The objective determination of vision and visual acuity. British Journal of Physiological Optics, 23, 107-127.

PotTer, M. C., Kroll, J. F., \& HARris, C. (1980). Comprehension 
and memory in rapid sequential reading. In R. Nickerson (Ed.), Attention and performance VIII. Hillsdale NJ: Erlbaum.

RAYNER, K. (1978). Eye movements in reading and information processing. Psychological Bulletin, 85, 618-660.

SLOAN, L. L., \& HABEL, A. (1973). Reading speeds with textbooks in large and in standard print. The Sight-Saving Review, 43, 107-112.

Stark, L., Vossius, G., \& Young L. R. (1962). Predictive control of eye tracking movements. Institute of Radio Engineers Transactions on Human Factors in Electronics, HFE-3, 52-57.

TAYLOR, E. A. (1937). Controlled reading. Chicago: University of Chicago Press.
Tinker, M. A. (1966). The bases for effective reading. Minneapolis: University of Minnesota Press.

WARD, N. J., \& Juola, J. F. (1982). Reading with and without eye movements: Reply to Just, Carpenter, and Woolley. Journal of Experimental Psychology: General, 111, 239-241.

Weigelin, E., Trier, H. G., Krischer, C. C., \& Meissen, R. (1979). First experiences with an instrument for TV display of digitally encoded text information for the visually handicapped. Graefe's Archive for Clinical and Experimental Ophthalmology, 209, 155-166.

(Manuscript received for publication December 10, 1984.) 